\title{
METODOLOGIA PARA A CONSTRUÇÃO DO REFERENCIAL ESTATÍSTICO DA UTILIZAÇÃO FÍSICA DE EQUIPAMENTOS DE MINA*
}

Fabiano Della Libera da Silva Roberto Francisco de Moraes

\section{Resumo}

Este artigo propõe uma metodologia para a construção de um Referencial Estatístico para a Utilização Física de equipamentos de mina. Para tanto, calcula-se um valor mensal (RE) apoiando-se em conceitos importantes para a operação de mina e que estão e inter-relacionados, como o comportamento sazonal da precipitação pluviométrica, o Teorema do Limite Central e a Gestão da Lacuna de Resultado. A metodologia proposta foi aplicada em uma mina de ferro a céu aberto e às frotas de transporte de um complexo minerador no Norte do Pará.

Palavras-chave: Metodologia; Referencial; Estatístico.

\section{METHODOLOGY FOR CONSTRUCTION OF STATISTICAL REFERENCE OF PHYSICAL USE OF MINE EQUIPMENT'S}

\begin{abstract}
This article proposes a methodology for the construction of a Statistical Reference for the Physical Use for mine equipment's. Therefore, we calculate a monthly value (RE) relying on important concepts for mine operation and are and interrelated, as the seasonal behavior of rainfall, the Central Limit Theorem and Management of Gap Result. The proposed methodology was applied in an iron ore open pit mine and on transport fleets of a mining complex in northern of Pará state.
\end{abstract}

Keywords: Methodology; Reference; Statistical.

1 Fabiano Della Libera da Silva: Engenheiro de Produção Civil, Mestre em Engenharia de Produção, Engenheiro de Operação de Mina, Operação de Mina de Carajás, VALE, Parauapebas, Pará, Brasil.

2 Roberto Francisco de Moraes: Engenheiro de Minas, Mestre em Engenharia de Produção, Gerente de Operação de Mina, Operação das Minas de N5 em Carajás, VALE, Parauapebas, Pará, Brasil. 


\section{INTRODUÇÃO}

A competitividade entre as empresas, indiferentemente do ramo em que estas atuam, fomenta de forma saudável uma busca pela melhoria no desempenho dos seus processos, principalmente pelo aumento do conhecimento e o domínio dos parâmetros que estão envolvidos nas mais variadas etapas que constituem os mesmos. Esta busca na melhoria é de fundamental importância, pois está diretamente relacionada com o aumento na produtividade, na melhor utilização dos ativos e, por consequência, para a redução nos seus custos produtivos, uma vez que isto é de primordial importância para a sobrevivência da empresa no mercado que atua.

Em um cenário caracterizado pela importância estratégica da informação e da disseminação do conhecimento nas empresas, de acordo com Nonaka e Takeuchi (1997), faz com que seja necessária a busca pela sobrevivência em longo prazo. Estes autores ainda enfatizam que cada ciclo pelos quais passou a evolução do pensamento moderno da engenharia, sempre estavam presentes fatores importantes como a melhoria das operações, a otimização dos processos, a eliminação de desperdícios, o surgimento de novas ferramentas, etc. Segundo Paim et al. (2009), um conjunto de princípios e técnicas como a automação dos processos, o Kanban, redução de tempos de setup, etc. foram estudadas pelos principais fundadores da Toyota, os senhores Toyodo Sakichi, Taiichi Ohno e Shigeo Shingo, com intuito de combater os desperdícios.

Este artigo se propõe uma metodologia sistematizada para a construção de um referencial estatístico para a determinação mais eficiente e representativa das horas improdutivas de cada natureza (que na prática são utilizadas no formato de códigos improdutivos) de modo que se tenha em curto ou médio prazo uma maior previsibilidade destas horas. As horas improdutivas de todos os códigos serão somadas ao final do período de apuração dos indicadores produtivos e, finalmente, teremos a quantidade total de horas que serão utilizadas na produção da mina. $O$ percentual de horas utilizadas em relação às horas disponíveis é chamado de Utilização Física (UF).

O artigo proposto está estruturado como segue. Na seção 2 é apresentada a fundamentação teórica do trabalho de forma a mostrar fatores importantes que deverão ser considerados para a concepção do método. A seção 3 faz um detalhamento da metodologia e os seus passos necessários para a sua aplicação, ao passo que a seção 4 traz um exemplo prático de aplicação da metodologia. $A$ seção 5 traz as considerações finais

\section{FUNDAMENTAÇÃO TEÓRICA}

Em uma mina à Céu Aberto, cada frente de lavra contém uma determinada quantidade de minério com características físicas, químicas e econômicas bem diferenciadas. Para satisfazer às especificações de qualidade exigidas pelos clientes, é necessário selecionar as frentes a serem lavradas e determinar seu ritmo de lavra. O material nas frentes de lavra poderá estar compactado oferecendo certa resistência para ser lavrado, ou seja, são ainda necessários processos de perfuração e desmonte de rochas para que o material in situ se torne não só trabalhável pelos equipamentos de escavação (escavadeiras ou pás carregadeiras) com também com características ideais exigidas pelos processos subsequentes à lavra (como por exemplo, britagem primária). Para a sua lavra, a mina conta com 
uma frota limitada de equipamentos os quais devem ser alocados às suas frentes e operarem em uma faixa de produtividade que torne viável sua utilização (COSTA, 2005).

A alocação de um equipamento de mina deve ser realizada de forma a utilizar ao máximo sua capacidade de produção, pois ela limita o ritmo de produção (lavra) da frente onde o mesmo está alocado devendo-se ainda, considerar a compatibilidade com os equipamentos de transporte (matching). Em se tratando de planejamento de lavra a céu aberto, em especial, na alocação de equipamentos de carga e caminhões em uma frente de lavra, cada frente contém minério com uma determinada quantidade, com características físicas, químicas e econômicas diferenciadas, denominadas parâmetros de controle.

Porter (1986) enfatiza que existe uma grande necessidade de integrarmos e analisarmos a cadeia de valor, de forma a envolvermos os setores que compõem os negócios de uma empresa, identificando o potencial para o alcance de vantagens competitivas em cada um dos processos de uma empresa.

Xavier (2005) afirma que a parceria entre a operação e a manutenção é de fundamental importância para o alcance da excelência. Essa parceria pode ocorrer através da formação de times em áreas específicas que podem ser utilizados para análise conjunta de: falha, problemas crônicos, desempenha de equipamentos, planejamento de serviços e até na programação diária.

O fator "integração manutenção e operação" ocupa a base do arco da gestão de manutenção proposto por Nyman e Levitt (2001). Na visão destes autores os demais fatores dependem deste relacionamento para sua construção, por exemplo, o fator "condição de ativos" não é só uma missão da manutenção, mas daqueles que estão no cotidiano operacional, sendo os mais presentes a manutenção e operação.

A estação chuvosa numa época do ano, podendo abranger um ou mais meses, é a época onde ocorre a maior parte da precipitação média anual em uma região. Em uma mina a céu aberto, os impactos da precipitação pluviométrica são bastante notórios e com sazonalidade definida e pode sofrer variações de acordo com a região em que a mina está situada. A erosão pluvial é provocada pela retirada de material da parte superficial do solo pelas águas da chuva trazendo consequências negativas para o processo de lavra além de demandar mais horas de trabalho de equipamentos de terraplanagem (tratores, motoniveladoras, etc.) para a correção de vias de acesso e leiras de proteção além de demandar mais horas de tratores nas pilhas de disposição de estéril.

A precipitação pluviométrica impacta também de forma direta os processos de escavação e transporte do minério nas frentes de lavra. Por exemplo, logo após a ocorrência de uma chuva muito intensa, é muito comum termos parte dos acessos dos caminhões (pista de rolagem) deformados em função do acúmulo de material estranho ou da ausência de material que compõe as vias de acesso na mina, ou pela presença de neblina onde se faz necessidade de parada dos equipamentos devido à visibilidade inadequada e, desta forma, interrompe-se a produção.

$\mathrm{Na}$ figura 01 abaixo temos o comportamento sazonal da precipitação pluviométrica (mm) - média mensal histórica entre 2000 e 2014 na mina de Carajás. 


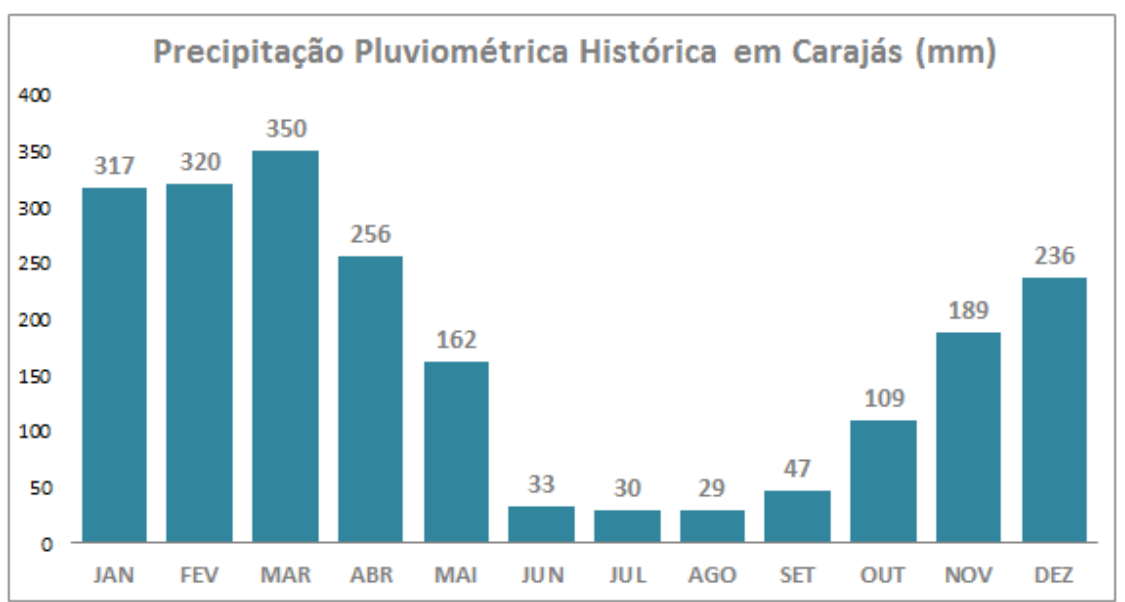

Figura 01 - Precipitação pluviométrica histórica em Carajás

No sistema de despacho, a parada dos equipamentos é efetuada através da aplicação de um código improdutivo no sistema do despacho da mina, ou seja, no momento da parada, o operador apropria no equipamento um código improdutivo e o sistema de despacho passa a contabilizar a duração do mesmo. Alguns códigos improdutivos são mais frequentemente utilizados no período chuvoso, pois sofrem influencia direta da precipitação pluviométrica, como por exemplo: "Mau TempoChuva"; "Ag. Condição de Acesso"; "Mau Tempo-Neblina".

A figura 02 abaixo mostra uma forte relação entre o percentual de horas disponíveis perdidas pelos caminhões (\%UF perdida) nestes três códigos improdutivos e a precipitação pluviométrica entre os anos de 2013 e 2015 na mina de Carajás.

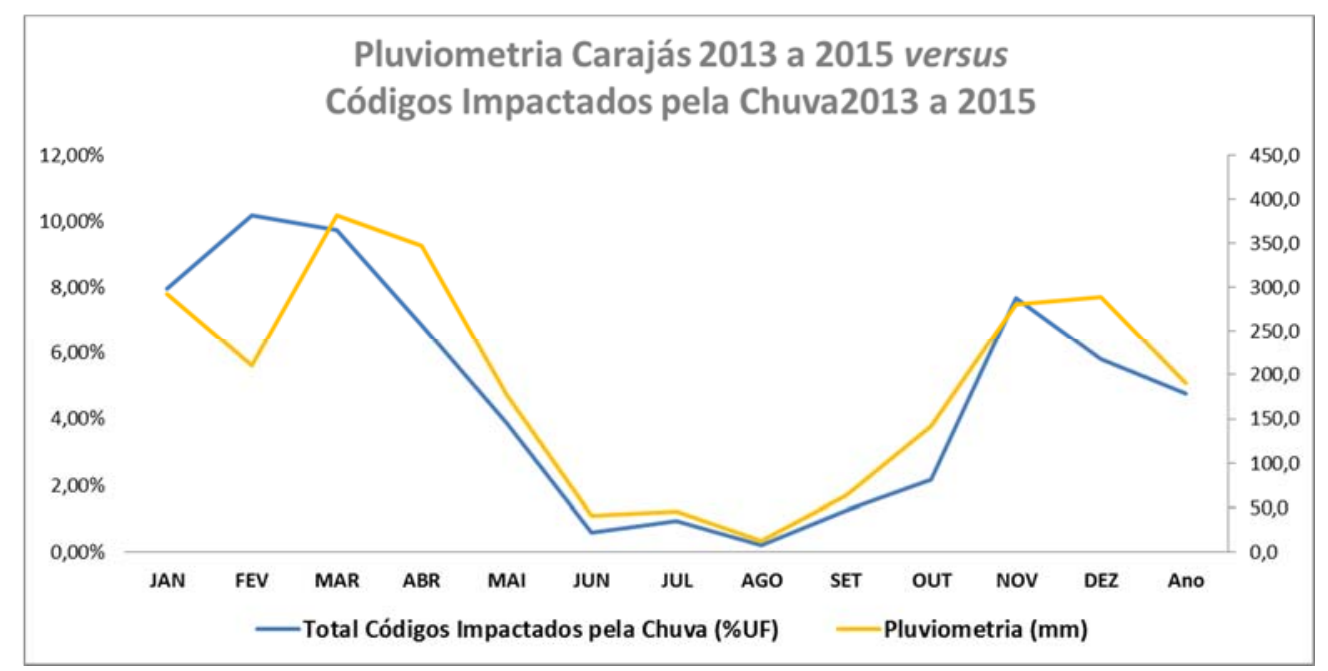

Figura 02 - Códigos improdutivos e a sua relação com a pluviometria de Carajás

\section{MÉTODO}

Esta seção a seguir detalha as etapas da metodologia utilizada para a definição do Referencial Estatístico dos códigos improdutivos.

\subsection{Análise do comportamento sazonal dos Códigos Improdutivos}

Nesta etapa, é avaliado o comportamento sazonal de cada código improdutivo do processo em questão. A importância desta etapa se torna mais evidente quando, no 
momento da projeção de curvas de utilização física de equipamentos, poderemos saber em qual mês projetaremos ganhos ou perdas de UF.

Para cada código improdutivo, deveremos estudar o seu comportamento mensal nos últimos anos para que se possa detectar a evolução do desempenho deste código nestes anos. A quantidade de anos ( $\mathrm{n}$ ) a serem estudados ficará a cargo do analista das informações onde o mesmo irá julgar o tamanho ideal de amostras. Como por exemplo, um "n" muito pequeno poderá nos levar a tomada de decisões equivocadas caso tivermos valores anormais em um determinado ano, ao passo de que um "n" muito grande, poderemos ter comportamentos em um determinado mês que foge às características atuais da mina, ou seja, a situação da mina atual se encontra muito diferente da estudada.

A figura 03 a seguir mostra uma forte influência da estação chuvosa na mina de Carajás sob o código improdutivo "Mau Tempo-Neblina".

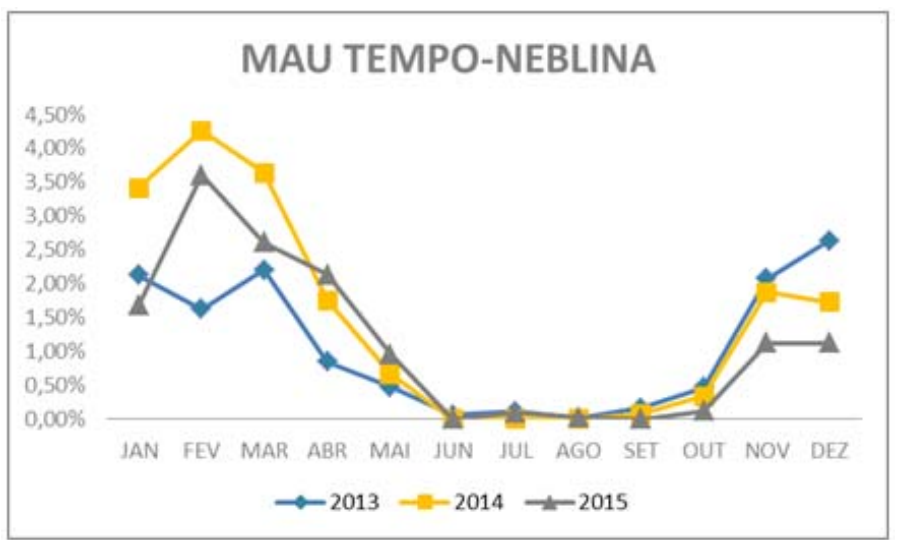

Figura 03 - Comportamento sazonal do código improdutivo "Mau Tempo-Neblina"

\subsection{Definição dos valores dos gap's Mensais (Deltas)}

Nesta etapa, para cada código improdutivo a ser estudado, serão avaliados os seus desempenhos mensais. Suponha que temos, para um determinado mês, a informações referente a três anos. Desta forma, a Equação (1) irá determinar o valor do delta $(\Delta)$ para cada mês:

Onde:

$$
\Delta=\text { ValorCentral-MenorValor }
$$

ValorCentral: É a mediana dos valores (P50); MenorValor: É o menor valor entre os dados

\subsection{Equalização de valores divergentes}

Uma vez calculados os deltas para cada mês e para cada código, podemos calcular o delta médio anual. Esta média anual corresponde à média dos deltas de todos os meses do ano, ou seja, de janeiro a dezembro. Caso tenhamos deltas mensais com valores acima do delta anual, passaremos a utilizar o delta anual.

\subsection{Cálculo do Desvio Padrão e definição do Referencial Estatístico}

Nesta etapa, será obtido o desvio padrão anual dos deltas mensais ( $\Delta$ Ajustado). Para cada mês e para cada código, será calculado o valor do Referencial Estatístico 
(RE) somando-se o valor do delta ajustado ao chamado "MenorValor", conforme mostra a equação (2) abaixo:

$\mathrm{RE}=$ MenorValor $+\Delta$ Ajustado

\subsection{Ajuste de valores Atípicos}

Nesta etapa são ajustados, quando necessário, alguns valores atípicos que porventura possam ser gerados pela metodologia. $\mathrm{O}$ ajuste é feito substituindo $\mathrm{o}$ valor atípico pelo valor mais adequado para o mês em questão. Este ajuste pode ser necessário em duas situações: uma é quando é aplicada a metodologia para algum código improdutivo e o método retorna, para algum mês ou período, valores atípicos quando se comparado com a curva de sazonalidade para o código em estudo

\section{APLICAÇÃO DO MÉTODO A UM SISTEMA PRODUTIVO}

Segue um exemplo de aplicação da metodologia nas frotas de caminhão na mina de ferro de Carajás, situada do sudeste do Pará.

Conforme o item 3.1, foram coletadas do sistema de despacho as informações das horas perdidas para cada código improdutivo (ao todo são 29 códigos) no período entre 2013 a 2015. Aqui estão sendo mostrados os dados já divididos pelas horas disponíveis (ou seja, em \%UF). Os piores resultados mensais dentre os anos estudados estão em vermelho, os resultados intermediários estão em amarelo e os melhores resultados estão na cor verde. A seguir, temos um exemplo para alguns códigos do que foi efetuado com todos os 29 códigos, conforme mostrado na figura 04 abaixo:

\begin{tabular}{|c|c|c|c|c|c|c|c|c|c|c|c|c|c|}
\hline \multicolumn{14}{|c|}{ SEM OPERADOR } \\
\hline $11,99 \%$ & $11,89 \%$ & $10,13 \%$ & $6,81 \%$ & $5,34 \%$ & $4,77 \%$ & $5,67 \%$ & $6,02 \%$ & $8,94 \%$ & $8,57 \%$ & $8,28 \%$ & $6,38 \%$ & $7,85 \%$ & 2013 \\
\hline $6,12 \%$ & $4,99 \%$ & $4,32 \%$ & $3,35 \%$ & $3,60 \%$ & $2,86 \%$ & $2,56 \%$ & $2,55 \%$ & $2,34 \%$ & $2,20 \%$ & $2,74 \%$ & $3,37 \%$ & $3,44 \%$ & 2014 \\
\hline $1,96 \%$ & $1,80 \%$ & $2,54 \%$ & $1,75 \%$ & $1,44 \%$ & $1,37 \%$ & $2,51 \%$ & $2,76 \%$ & $1,73 \%$ & $1,92 \%$ & $2,01 \%$ & $2,01 \%$ & $2,01 \%$ & 2015 \\
\hline \multicolumn{14}{|c|}{ PELA MANUTENCAO } \\
\hline $2,99 \%$ & 3,059 & $3,08 \%$ & $2,66 \%$ & $2,52 \%$ & $3,13 \%$ & $3,66 \%$ & $3,27 \%$ & $3,59 \%$ & $4,22 \%$ & $3,89 \%$ & $3,95 \%$ & $3,35 \%$ & 2013 \\
\hline $3,63 \%$ & $2,96 \%$ & $3,09 \%$ & $2,75 \%$ & $2,35 \%$ & $2,32 \%$ & $2,30 \%$ & $1,89 \%$ & $1,82 \%$ & $1,70 \%$ & $2,13 \%$ & $2,32 \%$ & $2,45 \%$ & 2014 \\
\hline $1,79 \%$ & $1,49 \%$ & $1,90 \%$ & $1,71 \%$ & $1,55 \%$ & $1,42 \%$ & $1,85 \%$ & $2,01 \%$ & $1,75 \%$ & $1,64 \%$ & $1,73 \%$ & $1,73 \%$ & $1,73 \%$ & 2015 \\
\hline \multicolumn{14}{|c|}{ AG.CONDICAO DE ACESSO } \\
\hline & $3,20 \%$ & $4,48 \%$ & $4,16 \%$ & $2,01 \%$ & 0,56 & $0,43 \%$ & $0,20 \%$ & $1,03 \%$ & $0,70 \%$ & $4,75 \%$ & $2,63 \%$ & $2,30 \%$ & 2013 \\
\hline $3,66 \%$ & $5,14 \%$ & $4,54 \%$ & $3,01 \%$ & $2,71 \%$ & $0,49 \%$ & $0,24 \%$ & $0,08 \%$ & $0,62 \%$ & $2,29 \%$ & $3,18 \%$ & $2,45 \%$ & $2,43 \%$ & 2014 \\
\hline $3,37 \%$ & $7,69 \%$ & $7,53 \%$ & $5,14 \%$ & $3,19 \%$ & $0,26 \%$ & $1,68 \%$ & $0,21 \%$ & $0,15 \%$ & $0,54 \%$ & $3,40 \%$ & $3,40 \%$ & $3,40 \%$ & 2015 \\
\hline \multicolumn{14}{|c|}{ TROCA DE TURNO } \\
\hline 2,01 & $1,87 \%$ & $1,90 \%$ & $2,14 \%$ & $2,08 \%$ & $1,99 \%$ & $2,00 \%$ & $1,94 \%$ & $1,87 \%$ & $1,93 \%$ & $1,72 \%$ & $1,80 \%$ & $1,94 \%$ & 2013 \\
\hline $1,74 \%$ & $1,92 \%$ & $1,97 \%$ & $2,05 \%$ & $2,08 \%$ & $2,23 \%$ & $2,14 \%$ & $1,95 \%$ & $1,69 \%$ & $1,54 \%$ & $1,81 \%$ & $1,86 \%$ & $1,91 \%$ & 2014 \\
\hline $1,68 \%$ & $1,72 \%$ & $2,05 \%$ & $2,14 \%$ & $2,10 \%$ & $2,37 \%$ & $2,34 \%$ & $2,34 \%$ & $2,06 \%$ & $2,01 \%$ & $2,08 \%$ & $2,08 \%$ & $2,08 \%$ & 2015 \\
\hline \multicolumn{14}{|c|}{ MAU TEMPO-NEBLINA } \\
\hline $2,13 \%$ & $1,63 \%$ & $2,20 \%$ & $0,85 \%$ & $0,47 \%$ & $0,06 \%$ & $0,11 \%$ & $0,01 \%$ & $0,17 \%$ & $0,46 \%$ & $2,07 \%$ & $2,63 \%$ & $1,06 \%$ & 2013 \\
\hline $3,42 \%$ & $4,26 \%$ & $3,64 \%$ & $1,76 \%$ & $0,67 \%$ & $0,00 \%$ & $0,00 \%$ & $0,00 \%$ & $0,07 \%$ & $0,34 \%$ & $1,88 \%$ & $1,73 \%$ & $1,54 \%$ & 2014 \\
\hline $1,68 \%$ & $3,61 \%$ & $2,62 \%$ & $2,14 \%$ & $0.96 \%$ & $0,00 \%$ & $0,09 \%$ & $0.02 \%$ & $0,00 \%$ & $0,28 \%$ & $1,30 \%$ & $1,30 \%$ & $1,30 \%$ & 2015 \\
\hline & & & or mais & & & Interm & Siário ( $P$ s: & & & mais Ba & & & \\
\hline
\end{tabular}

Figura 04 - Resultados de \%UF perdida por alguns códigos improdutivos

Em seguida, foram feitas as definições dos valores dos gap's Mensais (Deltas), conforme item 3.2. Aplicando-se a equação (1), teremos, para todos os meses do ano, os seguintes valores, conforme mostrado na figura 08 abaixo: 
$46^{\circ}$ Redução

$17^{\circ}$ Minério de Ferro

$4^{\circ}$ Aglomeração

ISSN 2176-3135

\begin{tabular}{|c|c|c|c|c|c|c|c|c|c|c|c|c|c|}
\hline JAN & FEV & MAR & $A B R$ & MAI & JUN & JUL & AGO & SET & OUT & NOV & DEZ & Ano & \\
\hline \multicolumn{14}{|c|}{ TROCA DE TURNO } \\
\hline $2,01 \%$ & $1,87 \%$ & $1,90 \%$ & $2,14 \%$ & $2,08 \%$ & $1,99 \%$ & $2,00 \%$ & $1,94 \%$ & $1,87 \%$ & $1,93 \%$ & $1,72 \%$ & $1,80 \%$ & $1,94 \%$ & 2013 \\
\hline $1,74 \%$ & $1,92 \%$ & $1,97 \%$ & $2,05 \%$ & $2,08 \%$ & $2,23 \%$ & $2,14 \%$ & $1,95 \%$ & $1,69 \%$ & $1,54 \%$ & $1,81 \%$ & $1,86 \%$ & $1,91 \%$ & 2014 \\
\hline $1,68 \%$ & $1,72 \%$ & $2.05 \%$ & $2,14 \%$ & $2,10 \%$ & $2,37 \%$ & $2,34 \%$ & $2,34 \%$ & $2.06 \%$ & $1,86 \%$ & $2.07 \%$ & $2.07 \%$ & $2,07 \%$ & 2015 \\
\hline $0,07 \%$ & $0,15 \%$ & $0,08 \%$ & $0,09 \%$ & $0,01 \%$ & $0,24 \%$ & $0,14 \%$ & $0,01 \%$ & $0,18 \%$ & $0,32 \%$ & $0,09 \%$ & $0,06 \%$ & $0,12 \%$ & Delta \\
\hline
\end{tabular}

Figura 05 - Cálculo do delta para cada mês

Considerando o mês de janeiro, obteremos o seguinte valor.

$\Delta=$ ValorCentral-MenorValor $=1,74 \%-1,68 \%=0,07 \%$

Em seguida, foi efetuada a equalização de valores divergentes, conforme o item 3.3. Para os valores individuais acima do valor da média mensal $(0,12 \%)$, consideraremos a média. Por exemplo, os meses de junho e julho assumiram o valor da média, pois estão acima desta, conforme mostrado na figura 06 abaixo

\begin{tabular}{|c|c|c|c|c|c|c|c|c|c|c|c|c|c|}
\hline JAN & FEV & MAR & $A B R$ & MAI & JUN & JUL & AGO & SET & OUT & NOV & DEZ & Ano & \\
\hline \multicolumn{14}{|c|}{ TROCA DE TURNO } \\
\hline $2,01 \%$ & $1,87 \%$ & $1,90 \%$ & $2,14 \%$ & $2,08 \%$ & $1,99 \%$ & $2,00 \%$ & $1,94 \%$ & $1,87 \%$ & $1,93 \%$ & $1,72 \%$ & $1,80 \%$ & $1,94 \%$ & 2013 \\
\hline $1,74 \%$ & $1,92 \%$ & $1,97 \%$ & $2,05 \%$ & $2,08 \%$ & $2,23 \%$ & $2,14 \%$ & $1,95 \%$ & $1,69 \%$ & $1,54 \%$ & $1,81 \%$ & $1,86 \%$ & $1,91 \%$ & 2014 \\
\hline $1,68 \%$ & $1,72 \%$ & $2,05 \%$ & $2,14 \%$ & $2,10 \%$ & $2,37 \%$ & $2,34 \%$ & $2,34 \%$ & $2,06 \%$ & $1,86 \%$ & $2,07 \%$ & $2,07 \%$ & $2,07 \%$ & 2015 \\
\hline $0,07 \%$ & $0,15 \%$ & $0,08 \%$ & $0,09 \%$ & $0,01 \%$ & $0,24 \%$ & $0,14 \%$ & $0,01 \%$ & $0,18 \%$ & $0,32 \%$ & $0,09 \%$ & $0,06 \%$ & $0,12 \%$ & Delta \\
\hline $0,07 \%$ & $0,12 \%$ & $0,08 \%$ & $0,09 \%$ & $0,01 \%$ & $0,12 \%$ & $0,12 \%$ & $0,01 \%$ & $0,12 \%$ & $0,12 \%$ & $0,09 \%$ & $0,06 \%$ & & Delta Ajust. \\
\hline
\end{tabular}

Figura 06 - Equalização de valores divergentes

De acordo com o item 3.4, será efetuado o cálculo do desvio padrão e definição do Referencial Estatístico (RE). O delta ajustado ( $\Delta$ Ajustado) é o valor do desvio padrão calculado a partir dos dados mensais equalizados, conforme mostrado na figura 07 . O seu resultado foi de $0,04 \%$.

\begin{tabular}{|c|c|c|c|c|c|c|c|c|c|c|c|c|c|c|}
\hline $\begin{array}{c}\text { JAN } \\
\text { TROCA D }\end{array}$ & $\begin{array}{c}\text { FEV } \\
\text { TURNO }\end{array}$ & MAR & $A B R$ & MAI & JUN & JUL & AGO & SET & OUT & NOV & DEZ & Ano & & \\
\hline $2,01 \%$ & $1,87 \%$ & $1,90 \%$ & $2,14 \%$ & $2,08 \%$ & $1,99 \%$ & $2,00 \%$ & $1,94 \%$ & $1,87 \%$ & $1,93 \%$ & $1,72 \%$ & $1,80 \%$ & $1,94 \%$ & 2013 & \\
\hline $1,74 \%$ & $1,92 \%$ & $1,97 \%$ & $2,05 \%$ & $2,08 \%$ & $2,23 \%$ & $2,14 \%$ & $1,95 \%$ & $1,69 \%$ & $1,54 \%$ & $1,81 \%$ & $1,86 \%$ & $1,91 \%$ & 2014 & \\
\hline $1,68 \%$ & $1,72 \%$ & $2,05 \%$ & $2,14 \%$ & $2,10 \%$ & $2,37 \%$ & $2,34 \%$ & $2,34 \%$ & $2,06 \%$ & $1,86 \%$ & $2.07 \%$ & $2,07 \%$ & $2,07 \%$ & 2015 & \\
\hline $0,07 \%$ & $0,15 \%$ & $0,08 \%$ & $0,09 \%$ & $0,01 \%$ & $0,24 \%$ & $0,14 \%$ & $0,01 \%$ & $0,18 \%$ & $0,32 \%$ & $0,09 \%$ & $0,06 \%$ & $0,12 \%$ & Delta & \multirow{3}{*}{$0,04 \%$} \\
\hline $0,07 \%$ & $0,12 \%$ & $0,08 \%$ & $0,09 \%$ & $0,01 \%$ & $0,12 \%$ & $0,12 \%$ & $0,01 \%$ & $0,12 \%$ & $0,12 \%$ & $0,09 \%$ & $0,06 \%$ & & Delta Ajust. & \\
\hline $1,72 \%$ & $1,76 \%$ & $1,94 \%$ & $2,09 \%$ & $2,12 \%$ & $2,03 \%$ & $2,04 \%$ & $1,98 \%$ & $1,73 \%$ & $1,58 \%$ & $1,76 \%$ & $1,84 \%$ & $1,88 \%$ & Ref. Técnica & \\
\hline
\end{tabular}

Figura 07 - Definição do Referencial Estatístico para cada mês

Através da aplicação da equação (2), são calculados os valores do Referencial Estatístico para cada mês. Abaixo temos o exemplo para o mês de janeiro.

$\mathrm{RE}=$ MenorValor $+\Delta$ Ajustado $=1,68 \%+0,04 \%=1,72 \%$

Conforme o item 3.5, serão ajustados a partir de agora os valores atípicos. Conforme mostrado na figura 08 , temos um exemplo de valores ajustados (valores na cor laranja). Como exemplo, para o mês de fevereiro, o valor calculado do Referencial Estatístico foi de 3,92\%, sendo um valor atípico para este mês conforme observado nos resultados dos dois últimos anos (8,14\% e 7,83\%), sendo assim, em função do valor muito atípico no ano de 2013 para este mês $(3,20 \%)$, este foi adequado para um valor mais coerente com a sazonalidade do código. 


\begin{tabular}{|c|c|c|c|c|c|c|c|c|c|c|c|c|c|}
\hline \multicolumn{14}{|c|}{ CÓDIGO IMPRODUTIVO (EXEMPLO) } \\
\hline JAN & FEV & MAR & ABR & MAI & JUN & JUL & AGO & SET & OUT & NOV & DEZ & Ano & \\
\hline $3,81 \%$ & $3,20 \%$ & $4,48 \%$ & $4,16 \%$ & $2,01 \%$ & $0,56 \%$ & $0,43 \%$ & $0,20 \%$ & $1.03 \%$ & $0,70 \%$ & $4,75 \%$ & $2,63 \%$ & $2,30 \%$ & 2013 \\
\hline $6,68 \%$ & $8,14 \%$ & $6,13 \%$ & $4,59 \%$ & $3.43 \%$ & $0,66 \%$ & $0,26 \%$ & $0,09 \%$ & $0,73 \%$ & $2.56 \%$ & $3,39 \%$ & $2,52 \%$ & $3,35 \%$ & 2014 \\
\hline $3,42 \%$ & $7,83 \%$ & $7,71 \%$ & $5,27 \%$ & $3,20 \%$ & $0,26 \%$ & $1,71 \%$ & $0,21 \%$ & $0,15 \%$ & $0,63 \%$ & $3,04 \%$ & $3,04 \%$ & $3,04 \%$ & 2015 \\
\hline $3,42 \%$ & $3,20 \%$ & $4,48 \%$ & $4,16 \%$ & $2,01 \%$ & $0,26 \%$ & $0,26 \%$ & $0,09 \%$ & $0,15 \%$ & $0,63 \%$ & $3,04 \%$ & $2,52 \%$ & $2,02 \%$ & Melhores Re \\
\hline $0,39 \%$ & $4,63 \%$ & $1,65 \%$ & $0,43 \%$ & $1,19 \%$ & $0,30 \%$ & $0,17 \%$ & $0,12 \%$ & $0,57 \%$ & $0,07 \%$ & $0,35 \%$ & $0,12 \%$ & $0,83 \%$ & Delta \\
\hline $0,39 \%$ & $0,83 \%$ & $0,83 \%$ & $0,43 \%$ & $0,83 \%$ & $0,30 \%$ & $0,17 \%$ & $0,12 \%$ & $0,57 \%$ & $0,07 \%$ & $0,35 \%$ & $0,12 \%$ & & Delta Ajust. \\
\hline $3,71 \%$ & $6,93 \%$ & $6,82 \%$ & $4,66 \%$ & $2,83 \%$ & $0,55 \%$ & $0,55 \%$ & $0,38 \%$ & $0,44 \%$ & $0,92 \%$ & $3,33 \%$ & $2,81 \%$ & $2,83 \%$ & rencial Estati \\
\hline
\end{tabular}

Figura 08 - Ajuste de valores atípicos

Para os códigos improdutivos "Sem Operador", "Ginástica Laboral" e "Lanche", conforme já previsto na seção 3.5, foram utilizados valores diferentes do calculado para todos os meses.

Após a apuração do percentual de perda de UF de todos os códigos, somam-se estas perdas e aplica-se na equação (3) a seguir:

$$
\% \text { UF= } 1-\% \text { PerdaUF }
$$

Como resultado final do método obtém-se uma curva de utilização física que leva em conta o comportamento sazonal de cada código de perda de utilização física e a sua distribuição mensal, conforme mostrado na figura 09 abaixo:

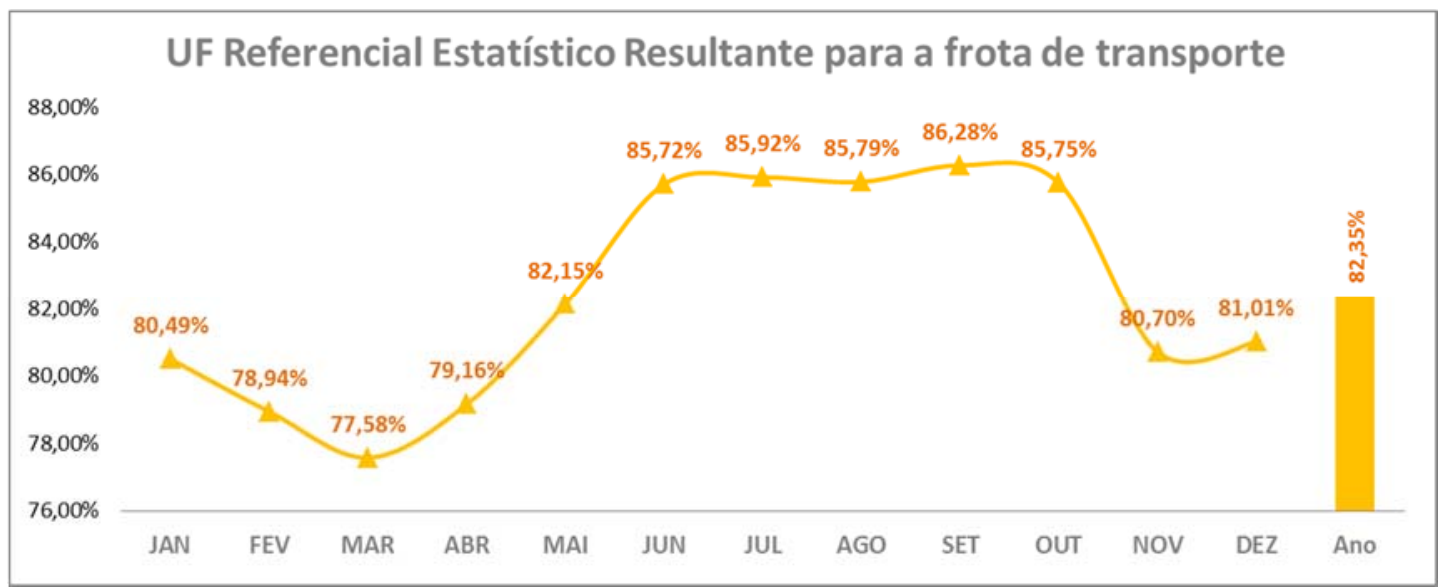

Figura 09 - Utilização Física do Referencial Estatístico

\section{CONCLUSÃO}

Este artigo apresentou uma proposta de Metodologia para a construção de um Referencial Estatístico para a determinação mais eficiente e representativa das horas improdutivas e, consequentemente, da UF de equipamentos de mina, tendo como objeto de estudo a frota de caminhões da mina de Carajás, porém, devido à similaridade nos processos de mineração e a inter-relação entre os diversos equipamentos que compõem estes processos, esta metodologia poderá ser extrapolada para outras frotas e outras minas.

A Metodologia apresentada apoia-se em conceitos importantes e que estão interrelacionados, como a correta operação dos equipamentos de mina, de alocação dinâmica através de sistemas de despacho eletrônico, o comportamento sazonal da precipitação pluviométrica, o Teorema do Limite Central e a Gestão da Lacuna de Resultado. A consideração destes fatores combinados nos permite ao mesmo tempo sabermos nossas limitações operacionais em função do comportamento sazonal de cada código de hora improdutiva e também a buscarmos a melhoria contínua no seu 
comportamento através da redução nos seus desvios padrão e também na busca de resultados cada vez mais perto dos melhores resultados.

A correta previsão da UF faz com que as empresas possam anteceder um cenário produtivo considerando, por exemplo, uma alteração em seu parque de equipamentos, ou até uma alteração no volume a ser produzido. Estas informações tem impacto direto no custo operacional da empresa. Como por exemplo, considerando-se que tenhamos uma baixa utilização física em um determinado período do mês (janeiro a abril e novembro a dezembro, conforme mostrado na Figura 12), e sabendo-se que existe uma forte correlação entre a pluviometria e a UF, teremos de ser mais cautelosos em projetarmos ganhos (aumento de UF) para alguns códigos mais relacionados com a precipitação pluviométrica, pois correremos um grande risco de não alcançarmos este suposto ganho e, por consequência, poderíamos obter um impacto negativo do não alcance da meta de massa movimentada na mina, que por sua vez tem impacto direto no custo de produção.

Como resultado do método apresentado, o Referencial Estatístico tem por finalidade não só de trazer um maior conhecimento do comportamento sazonal de cada um dos códigos de UF como também a busca contínua da melhoria no seu desempenho uma vez que a metodologia utiliza-se ao mesmo tempo de um benchmark histórico e de um gap de melhoria a ser atingida por cada código. Desta forma, uma vez que sejam alcançadas as melhorias desejadas, sugere-se que um novo referencial estatístico seja construído

\section{REFERÊNCIAS}

1 COSTA, F. P. (2005). Aplicações de técnicas de otimização a problemas de planejamento operacional de lavras em mina a céu aberto, Dissertação de mestrado, Programa de Pós-Graduação em Engenharia Mineral, Universidade Federal de Ouro Preto, $141 \mathrm{p}$.

2 NONAKA, Ikujiro; TAKEUCHI, Hirotaka. Criação de conhecimento na empresa: como as empresas japonesas geram a dinâmica da inovação. Rio de Janeiro: Campos 1997.

3 NYMAN, D., LEVITT, J. Maintenance planning, scheduling and coordination, New York: Industrial Press Inc., 2001

4 PAIM, R. et al. Gestão de processos: pensar, agir e aprender. Porto Alegre: Bookman, 2009.

5 PORTER, M. Estratégia Competitiva: Técnicas para Análise de Indústrias e da Concorrência, Rio de Janeiro, Campus, 1986.

6 XAVIER, J. N. Manutenção Classe Mundial. Congresso Brasileiro de Manutenção. Salvador: ABRAMAN, 2005. Acessado pelo site http://www.tecem.com.br/downloads/manutencao.pdf em 07/12/2015. 